Military Technical College Kobry El-Kobbah, Cairo, Egypt

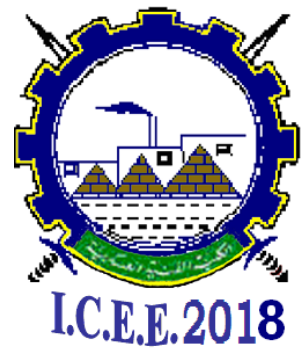

EPC-2 $9^{\text {th }}$ International Conference on

Chemical \& Environmental

Engineering

3-5 April 2018

\title{
Utilization of Anion Exchange Resins: Amberlyst A21 for Sulfate Reduction in Drinking Ground Water and its Characterization
}

\author{
Ahmed A Geies*, Mohamed Abdul-Moneim**and Seham O. Farghaly**
}

\begin{abstract}
Sulfate $\left(\mathrm{SO}_{4}\right)^{-2}$ is ubiquitous in groundwater, with both natural and anthropogenic sources. At high levels, sulfate can give water a bitter or astringent taste and can have mild laxative effects The aim of this work is to present experimental results on the evaluation and removal of Sulfate ions from drinking ground water in Wadi El-Assiuti - Egypt using anion exchange resin: Amberlyst A21. The drinking groundwater samples were collected from different places of ElFath region (Assiut Government) Egypt Amberlyst A21 was characterized by swelling, solubility, thermal properties like: thermal gravimetric analysis (TGA) and differential thermal gravimetric (DTG), X-ray diffraction analysis, and scanning electron microscopy (SEM) were also determined and the data were discussed. Moreover, the present study, anion exchange resins was used to the removal of sulphate $\left(\mathrm{SO}_{4}\right)^{-2}$ from ground water used as a drinking water. The effects of different parameters such as different resin dose, $\mathrm{pH}$ and contact time were examined. The results show that anion exchange resin (Amberlyst A21) has good affinity towards sulfate $\left(\mathrm{SO}_{4}\right)^{-2}$ ion removal that uses especial conditions such as large weight of resin or long time for treatment. And the loading increases with acidity. The Langmuir constants model for $\left(\mathrm{SO}_{4}\right)^{-2}$ ions are fitted well on the adsorption isotherms. The RL value in the present investigation was equal or less than one, indicating that the adsorption of $\left(\mathrm{SO}_{4}\right)^{-2}$ ion by Amberlyst A21 is favorable.
\end{abstract}

Keywords:

Drinking ground water, characterization, anion exchange resin Amberlyst A21, Sulfate Removal

*Chemistry Department and Geology Department**, Faculty of Science, Assiut University, Assiut, 71516, Egypt 
Military Technical College

Kobry El-Kobbah, Cairo, Egypt

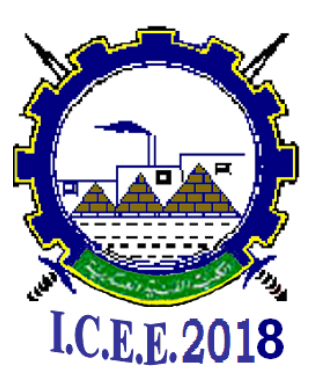

$9^{\text {th }}$ International Conference on

Chemical \& Environmental

Engineering

3-5 April 2018

\section{Introduction}

Sulfate is a ubiquitous component of the dissolved load of natural waters and has a wide variety of sources, both natural and anthropogenic. The anthropogenic sources of sulphate are often associated with inputs responsible for water quality deterioration, first of all by introduction of Sulfate with fertilizers or sewage and indirectly by precipitation of acid rain. Major natural sources of sulphate are cyclic marine salts (in coastal areas), weathering of sulfide minerals and dissolution of Sulfate evaporates.(1),(2) Weathering reactions can naturally supply large fluxes of sulphate to groundwater.(3) both from sulfide mineral oxidation,(4) and evaporates. (5), (6).Recent studies have shown that water table drawdown caused by changes in water abstraction can accelerate sulfide oxidation reactions. Subsurface conditions become more oxidizing during intense abstraction of water as shallow water is drawn into deeper flow paths and ore sulfide dispersed within the extended vadose zone is exposed to air, (7), (1), (8).Drinking water can come from different resources, such as it can pumped from the ground through wells, or prepared directly from surface water resources, such as rivers, lakes and streams. Clean drinking water is essential to humans and other life forms. Access to safe drinking water has improved steadily and substantially over the last decades in almost every part of the world. (8).Chemical contaminants of drinking water are often considered a lower priority than microbial contaminants, as adverse health effects from chemical contaminants are generally associated with long-term exposures, whereas the effects from microbial contaminants are usually immediate. Nonetheless, chemicals in water supplies can cause very serious problems. (9), (10)-The abundance of toxic chemicals in drinking water may cause adverse effect on the human health such as cancer and chronic illness. (11).Sulfate in drinking water has a secondary maximum contaminant level (SMCL) of $250 \mathrm{ppm}$, based on esthetic effects (i.e., taste and odor). (12).High concentrations of sulfate in ingested water can cause diarrhea in humans, especially infants (13).However, adults generally become accustomed to high sulfate concentrations after a few days. Sulfate in drinking water has a secondary maximum contaminant level (SMCL) of $250 \mathrm{mg} / \mathrm{L}$, based on aesthetic effects (i.e., taste and odor) (12). It is estimated that about $3 \%$ of the public drinking water systems in the United States may have sulfate concentrations of $250 \mathrm{mg} / \mathrm{L}$ or greater. (14)-Sulfate does not have a health-based drinking water standard. There is a maximum contaminant level (MCL) of $500 \mathrm{mg} / \mathrm{L}$ (parts per million). Sulfate has laxative effects and imparts an unpleasant taste to water. Aquifers with high concentrations of hydrogen sulfide have a bad odor. The Minnesota Department of Health (MDH) recommends a limit of $400 \mathrm{mg} / \mathrm{L}$ for water used in infant formula (see the $\mathrm{MDH}$ fact sheet Sulfate in Well Water). (15).Ion exchange has been applied in sulfate treatment because of the following advantages: 1) no secondary pollutanl, 2) very compact facility, 3) easy recovery of metals, and 4) more versatile than other methods. One problem often cited, the disposal of regeneration solution, has been solved by combination with other methods. (16) 
Military Technical College

Kobry El-Kobbah, Cairo, Egypt

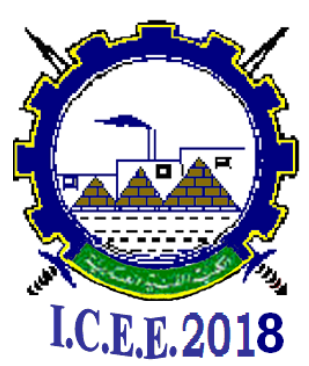

9 $\frac{\text { th }}{\text { International Conference }}$ on

Chemical \& Environmental

Engineering

3-5 April 2018

\section{Hydrogeological setting of Wadi EL-Assiuti}

Wadi EL-Assiuti area represents a segment of the Nile valley in Upper Egypt. It is location on the fringes of the flood plane east of Assiut city. The area is bounded by latitudes $27^{\circ} 5^{\prime} \mathrm{N}$ and $27^{\circ} 20^{\prime} \mathrm{N}$ and longitudes $31^{\circ} 10^{\circ} \mathrm{E}$ and $31^{\circ} 25^{\circ} \mathrm{E}$. The area is located in an arid region with almost no rainfall. Temperature varies from $5^{\circ} \mathrm{c}$ in winter to $45^{\circ} \mathrm{c}$ in summer. El fatah district is a part of Wadi EL-Assiuti area in Assiut governorate from its eastern side (Figure 1). Several studies were previously carried out on this study area for dealing with its evaluation of its ground water potentiality. The study area is a rectangular flat area of about $400 \mathrm{Km}^{2}$. It is bounded from the west by the Nile River and from the other sides by the limestone plateau that is dissected by a great number of wadis. Groundwater in this aquifer is characterized by fresh water. The salinity from 800 to $1000 \mathrm{ppm}$ The salt assemblages are: $\mathrm{Ca}\left(\mathrm{HCO}_{3}\right)_{2}, \mathrm{Mg}\left(\mathrm{HCO}_{3}\right)$, $\mathrm{NaHCO}_{3}, \mathrm{Na}_{2} \mathrm{SO}_{4}$ and $\mathrm{NaCl}$ which indicate a clear resemblance to the salt assemblages of surface water. The study of hydrochemical characteristics in Wadi El-Assiuti - Egypt revealed on the high concentration of Sulfate ion in some studied wells relative to(WHO2008), (EHCW2007). (17), (18)

\section{Material and Methods}

Twenty four water samples of drinking ground water have been collected from four pilot stations for drinking ground water at El Fath, El Wasta, El Masara, and El Fyama villages, Assiut governorate, for chemical analyses. The samples were collected in clean polyester bottles which were thoroughly rinsed with sample water and tightly sealed and labeled after collection. These samples were kept in refrigerated and transferred to the laboratory for analysis. All analyses were carried out in the geochemical laboratory of geology department, Faculty of Sciences, Assiut University. The average of chemical analyses results are given in Table (1).

\subsection{Sampling}

Water samples were randomly collected from private residencies at different 5 locations "districts". The study was undertaken at three different areas of Assiut valley considering the surroundings and distance. The sampling stations selected for the present study are:

Samples 1and 2: El-Fyama-Assiut.

Sample 3: El-Fyama (agriculture well) - Assiut.

Sample 4.1, 4.2, 4.3: Al Masara -Assiut.

Sample 5: El Wasta- Assiut.

Sample 6: El Fath- Assiut 
Military Technical College

Kobry El-Kobbah, Cairo, Egypt

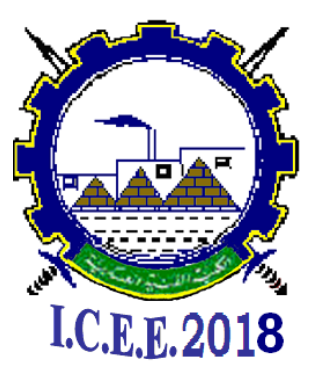

$9^{\text {th }}$ International Conference on

Chemical \& Environmental

Engineering

3-5 April 2018

Of each location, one drinking ground water sampling was taken from each location. Chemical studies were performed for of 24 samples have been collected periodically every two months (February to August 2011) from the previous stations. An interpretation of these results is achieved to define the physical and chemical characteristics of the drinking water in the studied areas.as shown in Table (1). No preservatives were added to any of the collected samples.

\subsection{Elemental analysis}

Analysis of the studied - Sulfate $\left(\mathrm{SO}_{4}\right)^{-2}$ was determined by photometric method using Kits. Samples were prepared according to APHA method (19).Instrument start- up and optimization was carried out as detailed in the operating manual. As showed in Table (1). Preparation of samples was carried out under clean conditions using deionized water. All chemicals and reagents used were of ultra-pure reagent grade (BDH laboratory reagents, Ltd Poole England). All glassware and plastic ware were washed three times with deionized water, and then soaked in $20 \%$ nitric acid overnight. After soaking the glass wares were rinsed three times with deionized water and dried. Quality assurance was achieved by measuring blank test solutions. Quality control was performed according to the specified conditions of the specific USEPA method, (2004) (20) by analysis of laboratory reagent blanks, fortified blanks and samples as a continuing check of performance. Rinse blanks and five calibrated standard solutions of all monitored analyses were used at part per million (ppm) or part per billion (ppb) concentration ranges for the different analyses.

\subsection{The chemical:-}

The anion exchange resins (Amberlyst A21) was purchased from Rohm and Haas USA and used in this study for the removal of sulfate from drinking water. The physical properties and specifications are presented previously in Table (1).

\subsection{Measurements}

FT-IR spectra were recorded on IR-470, Infrared spectrophotometer, Shimadzu by using the $\mathrm{KBr}$ pellet technique. The solubility of the anion exchange resin was examined using $0.02 \mathrm{~g}$ of resins in 3-5 $\mathrm{ml}$ of solvent at room temperature. The X-ray diffract graphs of the resin was obtained with a Philips X-ray PW1710 diffract meter, and $\mathrm{Ni}$ - filtered $\mathrm{CuK} \alpha$ radiations. Thermo gravimetric analysis (TGA) and differential thermal gravimetric (DTG) were carried out in air with Shimadzu DTG-60 at heating rate of $10^{\circ} \mathrm{C} / \mathrm{min}$. in air. The morphologies of the resin was examined by scanning electron microscopy (SEM) using a Jeol JSM-5400 LV instrument. 
Military Technical College

Kobry El-Kobbah, Cairo, Egypt

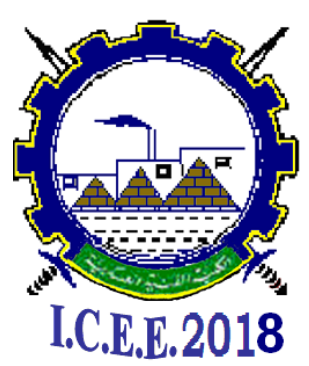

9 $\frac{\text { th }}{\text { International Conference }}$ on

Chemical \& Environmental

Engineering

3-5 April 2018

\section{Experimental}

\subsection{General procedure:}

\subsubsection{Batch experiments}

These experiments aimed to define the optimum conditions for sulfate sorption and the effects of (i) different resin dose(ii) $\mathrm{pH}$ (iii) contact time were examined (28)-, The experiments were performed by adding different dose (0.1 to $3 \mathrm{gm}$.) of the resin to $50 \mathrm{~mL}$ of contaminated water (known contamination values) from samples no.(3,4.2). From (El masara, and El Fyama (agriculture well) ) governorates .The contaminated water used could take from drinking ground water wells. The water samples with resin were left for 2 hour on stirrer using magnetic mixer on the room temperature. After that the resin was separated, the filtrate was analyzed by photometric method using Kits. And the results are given in Tables (5) In a 2nd second set of experiments, the effects of time and $\mathrm{pH}$ on sulfate removal from water were explored by varying the initial solution $\mathrm{pH}$ from (2) to (8.5) and time from $1 / 2 \mathrm{~h}$ to $13 \mathrm{~h}$. The equilibrium sulfate concentration was determined after .Using the above general procedure with the following anions:-

\subsubsection{Effect of different resin dose on sulfate removal}

The effect of changing initial resin dose $(0.1$ to $3 \mathrm{gm})$ on the removal of sulfate ions was examined at different values including loading by Amberlyst A21. On removal of SO4 ${ }^{-2}$ anions from samples no. $(3,4.2)$ from ( El masara ,and El Fyama) governorates. Due to its highest value, and equilibrated for $2 \mathrm{~h}$, while other operational parameters such as temperature and initial sulfate ion concentration of solutions were kept constant $\left(\mathrm{T}=25-30 \mathrm{C}^{\mathrm{\alpha}}\right.$, at $\mathrm{pH}=$ natural $)$. it was found that the removal efficiency is increased by increasing the resin dose and the $\mathrm{SO}_{4}{ }^{2-}(\%)$ removal reached a maximum value of $49 \%$ with resin dosage of $16 \mathrm{~g}$ for one liter contaminated water after 2hoursin sample no. ( 4.2) from ( $\mathrm{El}$ masara) or $22 \%$ with resin dosage of $9 \mathrm{~g}$ for one liter contaminated water after 2hours in sample no.( 3) from (El Fyama) Table( 5), Fig. (6). Also at more resin dose the removal \% becomes constant. This is probably because the resistance to mass transfer of sulfate from bulk liquid to the surface of the adsorbent and the saturation of active sites, which becomes important at high adsorbent loading in the system in which the experiment was conducted. It might have happened that the higher dose causes particle aggregates and interference or repulsive forces between binding sites, therefore, decreases the interaction of sulfate ions with the sorbent and reduces the total surface area of the adsorbent.(29)

\subsubsection{Effect of different time on sulfate removal}

Fig (7): depict sulfate loading by Amberlyst A21), at different time (0.5-2)h. At weights of the resin $(0.5) \mathrm{g}$ on removal of $\mathrm{SO}_{4}^{-2}$ anions from samples no.(3,4.2). From (El masara, and El 
Military Technical College

Kobry El-Kobbah, Cairo, Egypt

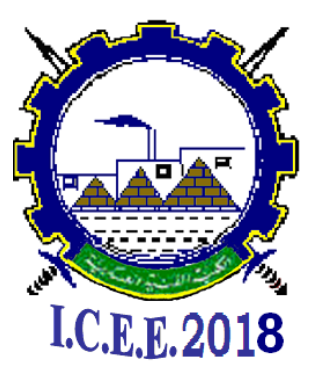

9 $\frac{\text { th }}{\text { International Conference }}$ on

Chemical \& Environmental

Engineering

3-5 April 2018

Fyama) (agriculture well) governorates it was found that the removal efficiency is increased by large increasing the time .and The SO4-2, removal reached a maximum value of $98 \%$ with resin dosage of $30 \mathrm{~g} / \mathrm{L}$ after 12 hours. After which concentration of sulfate in the solution decreases. This may be explained by the fact that initially for adsorption, large number of vacant sides was available, which slowed down later due to exhaustion of the remaining surface sites and repulsive force between solute molecule and bulk phase (30). As shown in Fig. (7).

\subsubsection{Effect of pH value on sulfate removal by Amberlyst A21}

The $\mathrm{pH}$ of exchanged ions is a very important character that determines the $\mathrm{pH}$ at which the ion exchange resin surface has net electrical neutrality. At this value, the acidic or basic functional groups no longer contribute to the $\mathrm{pH}$ of the solution (31). Fig (8) shows the effect of $\mathrm{pH}$ on sulfate ions removal from samples number $(3,4$, and 2$)$ from (El masara, and El Fyama onto $0.5 \mathrm{~g}$ of resins at different $\mathrm{pH}$ values $(2-8.5)$. The solution was agitated for $2 \mathrm{~h}$ and the residual sulfate ion in solutions was determined.And It was observed that the maximum removal percentage $(62 \%, 65 \%)$ from (El Fyama, and El masara) respectively .occurred at $\mathrm{pH} 3$. Also maximum adsorption at acidic $\mathrm{pH}$ indicates that the low $\mathrm{pH}$ leads to an increase in $\mathrm{H}^{+}$ions on the resin surface which results in significantly strong electrostatic attraction between positively charged anionic Amberlyst A21 resin surface and sulfate ions also this $\mathrm{pH}$ is encountered in many sites. Working at this $\mathrm{pH}$ (32) And the removal percentage of sulfate adsorption gradually decreased to $(23 \%, 29 \%)$ from (El Fyama, and $\mathrm{El}$ masara) respectively at $\mathrm{pH}$ 8.5.but at $\mathrm{pH}$ values greater than 8.5-9 adsorption of sulfate onto ion exchange resins were not significant due to anions competition to be exchanged on the surface of the prepared ion exchange resins of which $\mathrm{OH}-$ predominates. as shown in Fig. (8).

From all factors, it was found that the removal efficiency is increased by large increasing the resin concentration. Or by increasing the time and the loading increases with acidity.it was noted that the $\mathrm{SO}_{4}{ }^{-2}$ removal reached a maximum value of $65 \%$ from respectively .occurred at $\mathrm{pH} 3$ with resin dosage of $9 \mathrm{~g} / \mathrm{L}$ after 2 hours, or $49 \%$ with resin dosage of $16 \mathrm{~g} / \mathrm{L}$ for one liter

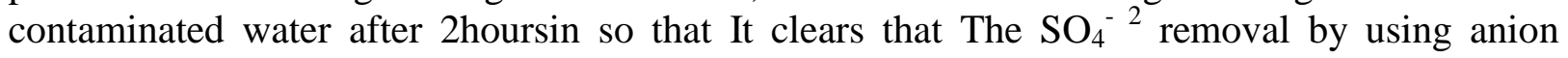
exchange Resin ( Amberlyst A21).is good .

\subsection{Adsorption Isotherm. Of $\mathrm{SO}_{4}{ }^{-2}$ Ion by (Amberlyst A21):}

Langmuir and Freundlich are the best models to explain the trend of adsorption based on the essence of absorbents saturated with adsorbate after enough contact time. (33), (34), (35), (36). which were carried out by contacting $0.5 \mathrm{~g}$ of the previous resin with different concentrations The equilibrium adsorption of sulfate Ion were carried out by contacting $1.5 \mathrm{~g}$ of the previous Amberlyst A21 with different sulfate concentrations (17,30,96, 115)ppm from the studded samples under room temperature, for $2 \mathrm{~h}$.and at solution $\mathrm{pH}$.on the shaker. The mixture was filtered; the final concentration of sulfate in solution was determined by measuring the 
Military Technical College Kobry El-Kobbah, Cairo, Egypt

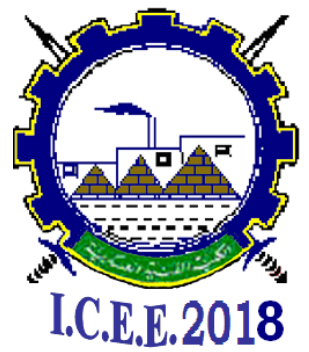

9 $\frac{\text { th }}{\text { International Conference }}$ on

Chemical \& Environmental

Engineering

3-5 April 2018

absorbance by spectrophotometer (using kits).And the data was fitted into the following isotherms: Langmuir, Freundlich, which are shown in Fig $(9 a, b)$.

\subsubsection{Langmuir adsorption isotherm is given as}

$$
q e=q \max \times C e \times K / 1+C e \times K
$$

Where $q e$ is the amount of the solute adsorbed per mass unit of adsorbent $(\mathrm{mg} / \mathrm{g}) ; C e$ is the equilibrium concentration of the aqueous phase $(\mathrm{mg} / \mathrm{L})$; and $q \max$ is the maximum. Amount adsorbed. The parameters, $q \max$ and $K$, are Langmuir constants. And qe can be calculated buy:

$$
q e=(C i-C e) V / X
$$

Where qe is the amount of the solute adsorbed per mass unit of adsorbent $(\mathrm{mg} / \mathrm{g}), \mathrm{Ci}$ is the initial concentration in the aqueous phase $(\mathrm{mg} / \mathrm{L}), C e$ is the concentration in the aqueous phase at equilibrium (mg/L), $V$ is the volume of the aqueous phase (L), and $X$ is the weight of the absorbent $(\mathrm{g})$.

\subsubsection{Freundlich isotherm}

The nonlinear form of Freundlich's equation is written as follows (37).

$$
q e=K f C^{1 / n}
$$

Where $q e$ is the amount of the solute adsorbed per mass unit of adsorbent $(\mathrm{mg} / \mathrm{g}), \mathrm{Ce}$ is the equilibrium aqueous pollutant concentration $(\mathrm{mg} / \mathrm{L}), K f$ is Freundlich constant, and $n$ is Freundlich exponent, $K f$ is the indicator of adsorption capacity, and $1 / n$ is a measure of intensity of adsorption.

Freundlich is an exponential equation which can be used to determine the values of parameters. The logarithm conversion is one way to determine Freundlich parameters. Therefore converts to $\log q e=\log K f+1 n \log C e$. By plotting $\log q e$ against $\log C e$, the values of Freundlich parameters can be determined. The slope of line is the exponent and the logarithm of intercept is the constant of Freundlich parameters.

Based on the data given in Table (6,7 and 8), the plots of $\log q e$ versus $\log C e$, and 1/qe versus $1 / C e$ were depicted to show the Langmuir and Freundlich isotherms, respectively Fig. ( 9 a, b). The results showed that Langmuir adsorption isotherm had better matching on data with $R^{2}=$ 0.93 than Freundlich adsorption isotherm with $R 2=-19$.that may be not obeyed the Freundlich isotherm. Also the characterization of the Langmuir equation can be explained in terms of the 
Military Technical College

Kobry El-Kobbah, Cairo, Egypt

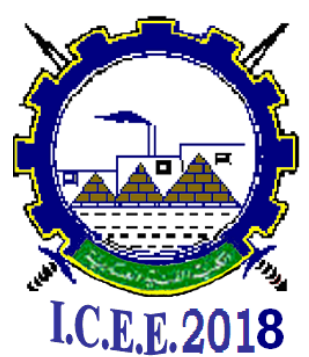

$9^{\text {th }}$ International Conference on

Chemical \& Environmental

Engineering

3-5 April 2018

equilibrium parameters $\left(\mathrm{R}_{\mathrm{L}}\right)$ which is a dimensionless constant referred to as separation factor or equilibrium parameter. (38).

$$
\mathrm{R}_{\mathrm{L}}=1 / 1+\left(\mathrm{K}_{\mathrm{L}}+\mathrm{C}_{0}\right)
$$

This factor describes the nature of the adsorption: irreversible $\left(\mathrm{R}_{\mathrm{L}}=0\right)$; favorable $\left(0<\mathrm{R}_{\mathrm{L}}<1\right)$; linear $\left(\mathrm{R}_{\mathrm{L}}=1\right)$; unfavorable $\left(\mathrm{R}_{\mathrm{L}}>1\right)$. (39). so that From the data calculated in Table (8), in the case of sulfate Ion removal the adsorption is favorable $\left(0<\mathrm{R}_{\mathrm{L}}<1\right)$; And From this research work, the maximum monolayer coverage capacity $\left(\mathrm{Q}_{\max }\right)$ from Langmuir Isotherm model was determined to be 0.7 and $\mathrm{K}_{\mathrm{L}}$ (Langmuir isotherm constant) is 0 . This again confirmed that the Langmuir isotherm was favorable for sorption of sulfate ion onto ion exchange resin amberlyst A2lunder the conditions used in this study. (37). (40)

\section{Results and Discussion}

\subsection{Characterization of Ion exchange resins: Amberlyst A21}

In this study, a chelating resin, as well as a anion exchange resin was contacted with aqueous solutions of Sulphate $\left(\mathrm{SO}_{4}\right)^{-2}$ in a complex form. The commercial ion exchange resin, is Amberlyst A21, solid acid resin catalysts, were obtained from Rohm and Haas Company (USA). All the experimental tests were conducted in batch stirred reactors. The various characteristics of the resins including: swelling, solubility, thermal properties like: thermal gravimetric analysis (TGA) and differential thermal gravimetric (DTG), X-ray diffraction analysis, and scanning electron microscopy (SEM) were also determined and the data are discussed below.

\subsection{Properties of the Resins:}

\subsubsection{Swelling}

Water swelling of an ion exchanger is primarily a hydration of the fixed ionic groups and increases with an increase in capacity to the limits imposed by the polymer network. Resin volumes change with conversion to ionic forms of differing degrees of hydration; thus, for a cation exchanger, there is a volume change with the monovalent ion species, $\mathrm{Li}^{+1}>\mathrm{Na}^{+1}>\mathrm{K}^{+1}$ $>\mathrm{Cs}^{+1}>\mathrm{Ag}^{+1}$ With polyvalent ions (21). To measure the swelling properties of the Amberlyst A21 sample, approximately $1.5 \mathrm{~g}$ of each catalyst was mixed with $4.0 \mathrm{ml}$ of solvent in gradated cylinder. The present swelling was measured in both methanol and water. The dry volume of the resin was taken immediately following the addition of the catalyst to the solvent. After an equilibration time of 5-10 minutes, the volume of the resin was recorded once again. This final volume was the volume after swelling. The\% swelling was then calculated by tacking the difference of the two volumes. Amberlyst A21 was obtained from the manufacturer in wet 
Military Technical College

Kobry El-Kobbah, Cairo, Egypt

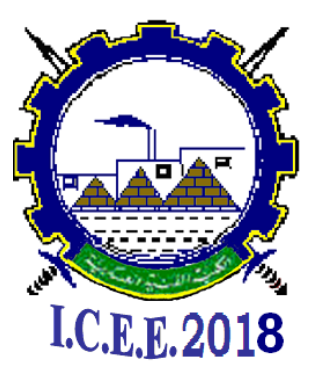

9 $\frac{\text { th }}{\text { International Conference }}$ on

Chemical \& Environmental

Engineering

3-5 April 2018

form, and it was dried overnight at $90{ }^{\circ} \mathrm{C}$ to remove water before the swelling experiments were carried out. Amberlyst A21, according to manufactures data, contained less than $2 \%$ water and was not dried further. Table 2 shows the results obtained from swelling experiments. The anion exchange resin swelled more in water than in methanol .Also Amberlyst A21 was very in their swelling properties,. One possible reason for the smaller swelling of Amberlyst A21 is that this resin has appreciably smaller average diameter of its internal pores $(=50 \mathrm{~A})$ This indicates more cross- linking and a more rigid polymer network Table ( 2).

\subsubsection{Solubility:}

The solubility characterizations of Amberlyst A21 were tested using various solvents including: dimethylformamide (DMF), dimethylsulfoxide (DMSO), dimeth-ylacetamide (DMA) tetrahydrofuran (THF), chloroform - acetone (1:1), methylene chloride, formic acid and conc. $\mathrm{H}_{2} \mathrm{SO}_{4}$ at room temperature. A $0.5 \%(\mathrm{w} / \mathrm{v})$ solution was taken as a criterion for solubility. (22).

It can be clarified from Table 3 that Amberlyst A21 is freely soluble in protonic acids like Formic and $\mathrm{H}_{2} \mathrm{SO}_{4}$ acids. In common organic solvents and halogenated hydrocarbons Amberlyst A21 is insoluble. In polar aprotic solvents, such as DMF, DMSO, DMA and THF, it showed partial solubility. Also, we found that Amberlyst A21 possesses better solubility due to the presence of polar groups with high steric effect than those containing $\mathrm{H}$ atoms which make the salvation easier Table (3).

\subsubsection{FT-IR spectra}

Spectral data support the structural assignment for the anion exchange resins, (23)-, and the FTIR data from $\mathrm{KBr}$ pellets for the two resins showed characteristic absorption due to, $\mathrm{CH}$ aliphatic groups at $2924.04 \mathrm{~cm}^{-1}$; $\mathrm{CH}$ aromatic at $3020 \mathrm{~cm}^{-1}$, and phenylene rings at 1635 $1510 \mathrm{~cm}^{-1}$. In addition, other characteristic bands, due to common groups present in various polymers were also shown Fig. (2).

\subsubsection{X- ray diffraction analysis:}

The X- ray diffractograms of Amberlyst A21 is shown in Fig. (3). The resin shows a halo peak lying in the region $2 \theta=5-60^{\circ}$. This indicates that there is a large class of structures that are in the amorphous phases (with pronounced long-range order) in the arrangement of their atoms and molecules. (24), (25).

\subsubsection{Thermal Gravimetric Analysis (TGA)}

The thermal behavior of the resin Amberlyst A21 was evaluated by TGA and DTG in air at a heating rate of $10^{\circ} \mathrm{C} \mathrm{min}{ }^{-1}$. TGA curves show a small weight loss in the range $2-4 \%$ starting at $90^{\circ} \mathrm{C}$ until $120^{\circ} \mathrm{C}$ which may be attributed to loss of observed moisture and entrapped solvents 
Military Technical College

Kobry El-Kobbah, Cairo, Egypt

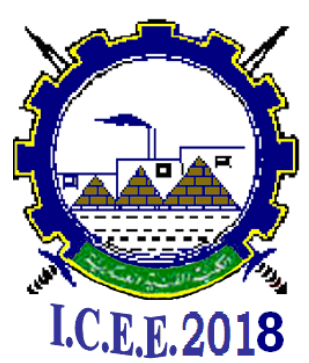

9 $\frac{\text { th }}{\text { International Conference }}$ on

Chemical \& Environmental

Engineering

3-5 April 2018

.The thermographs of both Amberlyst A21 is given in Fig. (4). while Table 4 gives the temperatures for various percentages weight loss. The initial decomposition of these polymers $\left(10 \%\right.$ loss) started at at $250^{\circ} \mathrm{C}$ for the resin. The expected nature of the decomposition of these polymers is through pyrolytic oxidation $\mathrm{C}=\mathrm{C}$ and rupture of many bonds. The degradation becomes maximal at around $510^{\circ} \mathrm{C}$ and is nearly complete at around $600{ }^{\circ} \mathrm{C}$. The temperature for $10 \%$ weight loss is considered to be the polymer decomposition temperature (PDT) (26). It occurs in the range $360-387^{\circ} \mathrm{C}$ for the resin. In Fig (4) mass loss is seen to be rapid between $\sim 340-392^{\circ} \mathrm{C}$ for resin in the first region, between $\sim 395-473^{\circ} \mathrm{C}$ in the second region and between $\sim 475-664^{\circ} \mathrm{C}$ in the third region. Table (4)

\subsubsection{Scanning electron microscopy (SEM) measurements:}

The morphological features of the resin were examined by scanning electron microscopy (SEM). The samples were prepared by putting a smooth part of the resin beads on a copper holder and subsequently coating it with gold palladium alloy. SEM images were taken on a Penta Z Z-50 P Camera with Ilford film at an accelerating voltage of $15 \mathrm{Kv}$ using a low-dose technique (27). This technique gives us the ability to show the surface of the polymers and to study the effect of structure on the surface of the selected polymer by comparison the images in each case. The study of the resin showed that the surface of the resin Amberlyst A21, (fig. 5a, $X=$ magnification $X=35$ ) consisted of spherical particles, with higher magnification $X=50$ (fig.5b) showed increasing in the spherical shape, while magnification of $X=75$ (fig.5c), and $\mathrm{X}=100$ (fig.5d) showed more particles in this shape.

\subsection{Evaluation of Cation and Anion exchange resin in purification of drinking groundwater}

Several techniques such as chemical precipitation, oxidation, reduction, coagulation, solvent extraction, and adsorption have been commonly employed for the removal of metal ions. Among these, ion exchange has been thought to be efficient and economically feasible as a wastewater treatment operation. Several resins can be used to remove metal ions; one of them is Amberlyst A21). In the present study, the anion exchange resin was used for the removal of sulfate ions from drinking ground water. The main objective of this study was to investigate the ability of it to remove the inorganic metals ions from water.

\section{Conclusions:}

The anion exchange resin named: Amberlyst A21, was used in the purification of drinking ground water in Wadi El-Assiuti - Egypt from Sulfate (SO4) ion. The resin was characterized by swelling, solubility, thermal properties like: thermal gravimetric analysis (TGA) and differential thermal gravimetric (DTG), X-ray diffraction analysis, and scanning electron 
Military Technical College

Kobry El-Kobbah, Cairo, Egypt

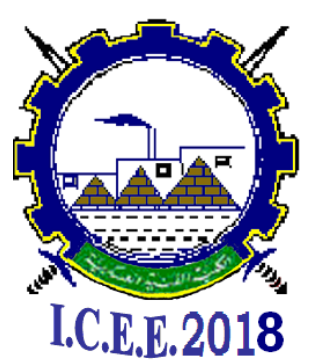

9 $\frac{\text { th }}{\text { International Conference }}$ on

Chemical \& Environmental

Engineering

3-5 April 2018

microscopy (SEM). At using (Amberlyst A21) for water treatment it was found that resin dose ,time and $\mathrm{pH}$ impacted sulfate specie removal: the SO42- uptake increased with the increase of resin dose and decreased with increasing $\mathrm{pH}$ values. It is also seen that a further increase in time affects the uptake of sulfate adsorption greatly. The results showed that the adsorption of sulfate ion onto the anion exchange resin Amberlyst A21 follow Langmuir adsorption isotherm so, it has good affinity towards the removal of this $\left(\mathrm{SO}_{4}\right)$ ion which needs especial conditions (such as large weight of resin at the low $\mathrm{pH}$ or long time) for its treatment.

\section{References}

[1] C.N.Alpers, J.L. Jambor, D.K Nordstrom,. (Eds.), Sulfate Minerals: Crystallography, Geochemistry and Environmental Significance. Mineralogical Society of America and the Geochemical Society, Washington, DC.( 2000).

[2] Samborska, H. Katarzyna, B. Stanislaw, H. Simon, Sources and impact of sulphate on groundwaters of Triassic carbonate aquifers, Upper Silesia, Poland Hydrology 486 (2013)136-150.

[3] Ulrich, A. Glenn, N. C. George, M. S. Isabelle, M. Joseph, Sources of sulfate supporting anaerobic metabolism in a contaminated aquifer. Environmental science \& technology,37(6)(2003) 1093-1099

[4] Moncaster, S.J., Bottrell, S.H., Tellam, J.H., Lloyd, J.W., Konhauser, K.O.,. Migration attenuation of agrochemical pollutants: insights from isotopic analysis of groundwater sulphate. J. Contam. Hydrol. 43(2000 )147-163.

[5] J. Gunn, , S.H.Bottrell, , D.J. Lowe, S.R.H.Worthington, Deep groundwater flow and geochemical processes in limestone aquifers: evidence from thermal waters in Derbyshire, J. England, UK. Hydrogeol. 14(2006) 868-881.

[6] Bardsley, I.H. Audra, E. B. Douglas, B.Theodore, H.T. Nikolaus -Small, Amy, Shallow groundwater conveyance of geologically derived contaminants to urban creeks in Southern California,j. Environmental science \& technology 49(16) (201`5) 9610-9619

[7] Mladenov, Z. Natalie, M. Yan, P N. Matthew, R L. Diana, S.Teresa, H. Bailey, R. Clarissa, M M. Ahmed, K M.McKnight, M. Diane, Dissolved organic matter sources and consequences for iron and arsenic mobilization in Bangladesh aquifers,j. Environmental science \& technology,44(1)(2009) 123-128

[8] Agrawal, P. Anju, S S.Ravi, Bechan, Water pollution with special reference to pesticide contamination in India, J. Water Resource and Protection,2(2010 )432

[9] a,b. Lomborg and Björn The Skeptical Environmenta list. Cambridge University Press. (2001) p. 22. ISBN 0521010683.

[10] Villanueva, M K. Cristina, C. Manolis, T.Sylvaine, R V. Michael, N. Roel, R N. John, J L. Mark, Patrick, Assessing exposure and health consequences of chemicals in drinking 
Military Technical College

Kobry El-Kobbah, Cairo, Egypt

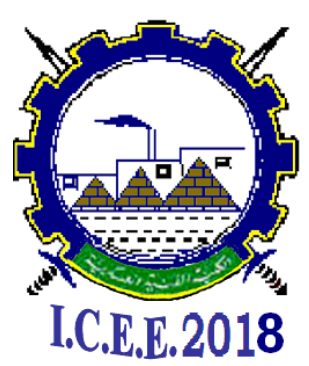

9 $\frac{\text { th }}{\text { International Conference }}$ on

Chemical \& Environmental

Engineering

3-5 April 2018

water: current state of knowledge and research needs ,j. Environmental health perspectives, 122(3)(2014) 213

[11] Shin, L.Jinho, C. Dianliang, K. Christoph, W.Ivana, David, International regulatory requirements for vaccine safety and potency testing: a WHO perspective\&,j. Procedia in Vaccinology,5(2011) 164-170

[12] Dietrich, M. B. Andrea, A.Gary, Critical review and rethinking of USEPA secondary standards for maintaining organoleptic quality of drinking water, j. Environmental science \& technology, 49(2) (2015)708-720

[13] Stuer-Lauridsen, B. Frank, H. Morten, LP Lützhøft, H-C H. Halling-Sørensen, Bent , Environmental risk assessment of human pharmaceuticals in Denmark after normal therapeutic use ,j. Chemosphere,40(7)(2000) 783-793

[14] Batt, Angela L Snow, Daniel D Aga, Diana SOccurrence of sulfonamide antimicrobials in private water wells in Washington County, Idaho, USA, j., Chemosphere, 65(11) ( 2006)1963-1971

[15] Schneider and Edward, Sulfate in Well Water-EH: Minnesota Department of Health,j. health,.800( 2004) 383-9808

[16] Kim, L. Seung-Jai, J. Ki-Hyun, L. Kwang-Hyun, K.Myung-Jin, C. Sang-Gyu, Sung-Yong, Removal of heavy metal-cyanide complexes by ion exchange,j. Korean Journal of Chemical Engineering,19( 6)(2002) 1078-1084

[17] WHO 2008 Guidelines for drinking-water quality, 3rd ed, Genebra, p. 668.,

[18] Egyptian Higher Committee for Water (EHCW), :Egyptian standards for drinking and domestic uses. (In Arabic), (2007) Cairo

[19] Federation, Water Environmental American Public Health Association, Standard methods for the examination of water and wastewater. American Public Health Association (APHA): Washington, DC, USA (2005)

[20] A Baba, A Kaya - Leaching characteristics of solid wastes from thermal power plants of of and comparison of toxicity methodologies, j. Environmental Management, 73(3)(2004)199-207.

[21] Nasef, M.H. Mohamed, A.El-Sayed, Preparation and applications of ion exchange membranes by radiation-induced graft copolymerization of polar monomers onto nonpolar films, j.Progress in Polymer Science, 29(6)(2004)499-561

[22] Toledano, O.Manuel, O. Raquel, F. Estrella, P.Victoria, G.-G. Carlo, Franklin Sorption and solubility of resin-based restorative dental materials , J. dentistry,31(1) (2003)43-50

[23] Zheng, J. Ming, S. Anand, S S. Michael, P B. Adelina, C. Paul, S Grace Diner, Bruce A Dresselhaus, Mildred S Mclean, Robert S Onoa, G Bibiana, Structure-based carbon nanotube sorting by sequence-dependent DNA assembly,j. Science,302(2003)5650

[24] Gheorghieş and Constantin Analysis of the superficial layer by X-rays diffraction method,j. Annals , 24(2003)26 
Military Technical College

Kobry El-Kobbah, Cairo, Egypt

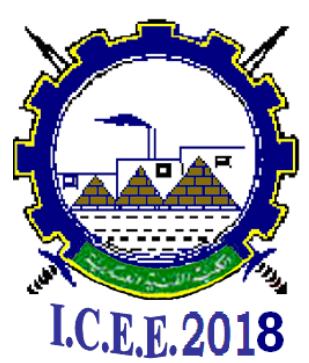

9 $\frac{\text { th }}{\text { International Conference }}$

on

Chemical \& Environmental

Engineering

3-5 April 2018

[25] Cheng, S. Shan, M L. Derrick, Y .Christopher, Anisotropic Ion Transport in a Poly (ethylene oxide)-LiClO4 Solid State Electrolyte Template by Graphene Oxide ,j. Macromolecules, 48(13)(2015)4503-4510

[26] K. I .Aly, M. A .S. Hussein, M. Marwa Liquid crystalline polymers XII. Main chain thermo tropic poly (arylidene-ether) s containing 4-tertiary-butyl-cyclohexanone moiety linked with polymethylene spacers,j.Liquid Crystals, 40(11)(2013)1570-1580

[27] Seraffon and Maud ,Performances of air plasma sprayed thermal barrier coatings for industrial gas turbines (2012).

[28] Feng, G. Yuan, L. Z. Ji-, Guang-M. N. M., Y. Z. Qiu-, Y. N.Hui, G. D. Cheng, H. Y. M. Jiu Adsorption of $\mathrm{Cd}$ (II) and $\mathrm{Zn}$ (II) from aqueous solutions using magnetic hydroxyapatite nanoparticles as adsorbents,j. chemical Engineering Journal, 162(2) (2010) 87-494

[29] S .Koumaiti, K .Riahi, F. Ounaies, B. Ben Thayer; J. Environ Sci Eng 5(2011) 1570-1580

[30] Nadaroglu, K. Hayrunnisa, Ekrem. Removal of cobalt (II) ions from aqueous solution by using alternative adsorbent industrial red mud waste material,j. International Journal of Physical Sciences,7(9) (2012) 1386-1394

[31] S. ApteSagar, S .ApteShruti, VS. Kore, SV .Kore Universal J Environ Res Technol 1(4) (2011) 416-422

[32] Damaris Guimarães *, Versiane A. Leão, Batch and fixed-bed assessment of sulphate removal by the weak base ion exchange resin Amberlyst A21, J. Hazardous Materials 280 (2014) 209-215

[33] F. W.Hamdi, Gamaoun, D. E. Pelster, ,and, M Seffen "Nitrate sorption in an agricultural soil profile," Applied and Environmental Soil Science, 2013, Article ID 597824.(2013) 7

[34] N. P. Qafoku, , M. E. Sumner, and D. E. Radcliffe, ,Anion transport in columns of variable charge subsoils: nitrate and chloride," J. Environmental Quality, 29(2), (2000) 484-493,

[35] Bhatnagar, A. Kumar, E. and Sillanpaa, M. "Nitrate removal from water by nanoalumina: characterization and sorption studies, J. Chemical Engineering 163(3(2010) $317-323$

[36] J .Hizaland R. Apak, Modeling of cadmium(II) adsorption on kaolinite-based clays in the absence and presence of humic acid,J. Applied Clay Science, 32, (3-4) (2006) 232-244.

[37] Zheng C. and Bennett G. D. ( 2002) Applied Contaminant Transport Modeling, John Wiley \& Sons, J. Inc., New York( 2002), 621

[38] Pandey, PK Sharma, SK Sambi, SS, Kinetics and equilibrium study of chromium adsorption on zeoliteNaX,J. International Journal of Environmental Science \& Technology,7(2)(2010) 395-404

[39] ALzaydien, Atef S, Adsorption of methylene blue from aqueous solution onto a low-cost natural Jordanian Tripoli,J. American Journal of Applied Sciences,6(6)(2009) 1047 
Military Technical College

Kobry El-Kobbah, Cairo, Egypt

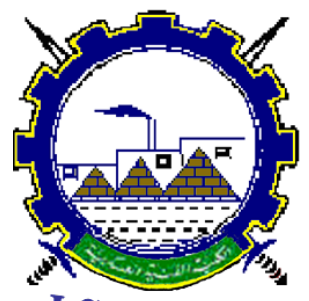

I.C.E.E.2018 $9^{\text {th }}$
International Conference
on

Chemical \& Environmental

Engineering

3-5 April 2018

[40] Ünlü, Nuri Ersoz, Mustafa, Adsorption characteristics of heavy metal ions onto a low cost biopolymeric sorbent from aqueous solutions,J. Hazardous Materials, 136 (2) (2006) 272280. 
Military Technical College Kobry El-Kobbah, Cairo, Egypt

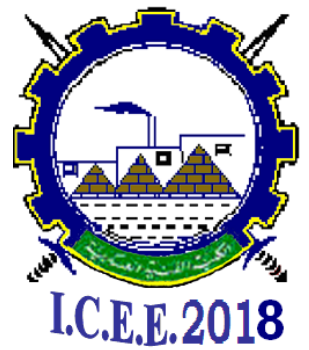

$9^{\text {th }}$ International Conference on

Chemical \& Environmental

Engineering

3-5 April 2018

Table (1): Results of physical and chemical analyses of the water samples collected from the drinking groundwater wells in the study area.

\begin{tabular}{|c|c|c|c|c|c|c|c|c|c|c|c|c|c|c|}
\hline \multirow{2}{*}{ 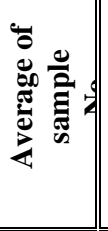 } & \multirow{2}{*}{ 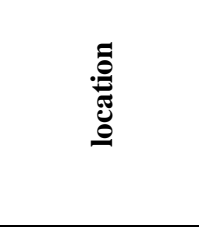 } & \multirow[t]{2}{*}{ pH } & \multirow{2}{*}{ 诖 } & TDS & $\mathrm{Ca}^{+2}$ & $\mathbf{M g}^{+2}$ & TH & $\mathrm{Na}^{+1}$ & $\mathrm{~K}^{+1}$ & $\mathrm{CO}_{2}^{-}$ & $\mathrm{HCO}_{1}^{-}$ & $\mathrm{Cl}^{-1}$ & $\mathrm{SO}_{2}^{-}$ & $\mathrm{NO}_{3}{ }^{-1}$ \\
\hline & & & & \multicolumn{11}{|c|}{ ppm } \\
\hline 1 & ElFayama(1) & 7.8 & 1002 & 540 & 45 & 11 & 158 & 98 & 9 & 10 & 42 & 110 & 30 & 7 \\
\hline 2 & ElFayama(2) & 7.9 & 1010 & 546 & 45 & 11 & 160 & 97 & 9 & 10 & 30 & 106 & 13 & 10 \\
\hline 3 & ElFayama(3) & 8.1 & 2005 & 820 & 56 & 12 & 189 & 138 & 14 & 10 & 101 & 80 & 155 & 16 \\
\hline $4(1)$ & Elmasra(1) & 8.2 & 2016 & 811 & 35 & 12 & 137 & 87 & 9 & 3 & 90 & 75 & 5 & 17 \\
\hline $4(2)$ & Elmasra(2) & 8.1 & 1009 & 400 & 34 & 11 & 131 & 75 & 8 & 8 & 31 & 90 & 112 & 19 \\
\hline $4(3)$ & Elmasra(3) & 7.7 & 1005 & 680 & 39 & 12 & 146 & 125 & 10 & 14 & 41 & 110 & 96 & 45 \\
\hline 5 & Elwasta & 8 & 405 & 170 & 14 & 10 & 78 & 38 & 7 & 2 & 32 & 40 & 25 & 14 \\
\hline 6 & Elfatah & 7.9 & 706 & 350 & 35 & 11 & 134 & 56 & 8 & 3 & 60 & 60 & 17 & 13 \\
\hline
\end{tabular}

Table 2: \% Swelling of Amberlyst A21 in Water and Methanol

\begin{tabular}{||c||c|c||}
\hline $\begin{array}{c}\text { Type of ion exchange } \\
\text { resin }\end{array}$ & \% Swelling in Water & \% Swelling in Methanol \\
\hline \hline Amberlyst A21 & 28 & 23 \\
\hline
\end{tabular}

Table (3): Solubility characteristics of anion Exchange Resins Amberlyst A21

\begin{tabular}{|c|c|c|c|c|c|c|c|c|}
\hline $\begin{array}{l}\text { Type of } \\
\text { anion } \\
\text { exchange } \\
\text { resin }\end{array}$ & DMF & DMSO & DMA & THF & $\begin{array}{c}\text { Chloroform } \\
+ \text { Acetone } \\
(1: 1)\end{array}$ & $\mathrm{CH}_{2} \mathrm{Cl}_{2}$ & $\mathrm{HCOOH}$ & $\begin{array}{c}\text { Conc } \\
\mathrm{H}_{2} \mathrm{SO}_{4}\end{array}$ \\
\hline $\begin{array}{l}\text { Amberlyst } \\
\text { A21 }\end{array}$ & + & + & + & - & + & - & ++ & ++ \\
\hline
\end{tabular}


Military Technical College Kobry El-Kobbah, Cairo, Egypt

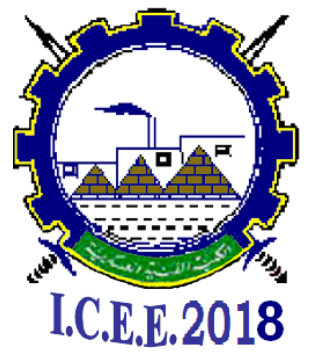

$9^{\text {th }}$ International Conference on

Chemical \& Environmental

Engineering

3-5 April 2018

Table (4): Thermal properties of Resin Amberlyst A21

\begin{tabular}{|c||c|c|c|c||c||}
\hline \multicolumn{1}{|c||}{$\begin{array}{l}\text { Type of anion } \\
\text { exchange resin }\end{array}$} & \multicolumn{3}{|c|}{ Temperature $\left({ }^{\circ} \mathbf{C}\right.$ ) for various \% decomposition * } \\
\cline { 2 - 6 } & $10 \%$ & $20 \%$ & $30 \%$ & $40 \%$ & $50 \%$ \\
\hline \hline Amberlyst A21 & 250 & 310 & 360 & 405 & 450 \\
\hline
\end{tabular}

* The values were determined by TGA at heating rate of $10{ }^{0} \mathrm{C} / \mathrm{min}$.

Table 5: Results of effect of different resin dose on removal of sulfate by Amberlyst A21

\begin{tabular}{|c|c|c|c|c|c|c|}
\hline \multirow{3}{*}{$\begin{array}{l}\text { Metals } \\
\text { ion }\end{array}$} & \multicolumn{2}{|c|}{$\begin{array}{c}\mathrm{SO4}^{-2} \text { concentration }(\mathrm{ppm}) \\
\text { Before treatment from }\end{array}$} & \multirow{3}{*}{$\begin{array}{l}\text { Wt. Of } \\
\text { resin }\end{array}$} & \multirow{3}{*}{ Time(h) } & \multirow{2}{*}{\multicolumn{2}{|c|}{ 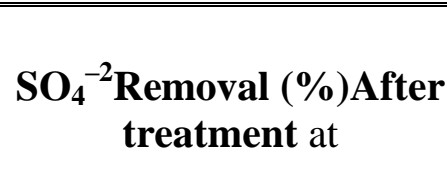 }} \\
\hline & \multirow{2}{*}{ El fayama } & \multirow{2}{*}{ El masara } & & & & \\
\hline & & & & & El fayama & El masara \\
\hline \multirow{5}{*}{$\mathrm{SO}_{4}{ }^{-2}$} & \multirow{5}{*}{155} & \multirow{5}{*}{112} & 0.5 & \multirow{5}{*}{2} & 0 & 5 \\
\hline & & & 1 & & 2 & 13 \\
\hline & & & 1.5 & & 22 & 35 \\
\hline & & & 2 & & 22 & 49 \\
\hline & & & 3 & & 22 & 49 \\
\hline
\end{tabular}

Table (6): Parameters for plotting Langmuir and Freundlich Adsorption Isotherms of sulfate ion removal by (Amberlyst A21)

\begin{tabular}{|c|c|c|c||c||c||c|}
\hline & Ce(ppm) & $\mathbf{Q e}(\mathbf{m g} / \mathbf{g}))$ & 1/ $\boldsymbol{e}$ & $\mathbf{1 / q} \boldsymbol{L}$ & $\begin{array}{l}\text { Log. } \\
\text { Ce }\end{array}$ & Log. $\boldsymbol{e}$ \\
\hline \hline 17 & 8.2 & 8.8 & 0.12 & 0.11 & 0.9 & 0.99 \\
\hline \hline 30 & 19 & 11 & 0.05 & 0.09 & 1.3 & 1.09 \\
\hline \hline 96 & 76.8 & 19.2 & 0.013 & 0.05 & 1.9 & 1.28 \\
\hline \hline 115 & 89.7 & 25.3 & 0.01 & 0.039 & 2 & 1.4 \\
\hline
\end{tabular}


Military Technical College Kobry El-Kobbah, Cairo, Egypt

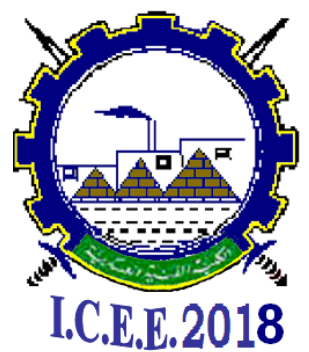

$9^{\text {th }}$ International Conference on Chemical \& Environmental Engineering 3-5 April 2018

Table (7): Linear regression equations Langmuir and Freundlich isotherm and constants for adsorption of sulfate Ion by (Amberlyst A21)

\begin{tabular}{|c|c|c|c|c|c|}
\hline Metal & \multirow{2}{*}{ Type of Resin } & \multicolumn{3}{|c|}{ Langmuir Adsorption } & \multirow{2}{*}{ Langmuir equations } \\
\hline \multirow{2}{*}{$\mathrm{So}_{4}{ }^{-2}$} & & $q_{\max }(\mathrm{mg} / \mathrm{g})$ & $\begin{array}{c}\mathbf{K L}(\mathbf{L} / \mathbf{m} \\
\mathrm{g})\end{array}$ & $\overline{\mathbf{R}^{2}}$ & \\
\hline & Amberlyst A21 & 0.77 & 0 & 0.7 & $Y=0.77 x$ \\
\hline \multirow{3}{*}{$\mathrm{So}_{4}{ }^{-2}$} & \multirow{3}{*}{ Amberlyst A21 } & \multicolumn{3}{|c|}{ Freundlich Isotherm } & \multirow{2}{*}{ Freundlich equations } \\
\hline & & $\mathbf{n}$ & $k_{f}(\mathrm{mg} / \mathrm{g})$ & $\mathbf{R 2}$ & \\
\hline & & 1.3 & 0 & 0.68 & $Y=1.3 x$ \\
\hline
\end{tabular}

Table (8). RL values for sulfate Ion concentrations

\begin{tabular}{|c|c|c|}
\hline $\begin{array}{c}\begin{array}{c}\mathrm{So}_{4}{ }^{-2} \mathrm{Ion} \\
\text { concentration } \\
(\mathrm{ppm})\end{array} \\
\end{array}$ & Type of resin & 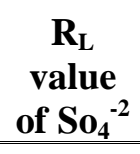 \\
\hline 17 & \multirow{4}{*}{$\begin{array}{c}\text { Amberlyst } \\
\text { A21 }\end{array}$} & 0.05 \\
\hline 30 & & 0.03 \\
\hline 96 & & 0.01 \\
\hline 115 & & 0.009 \\
\hline
\end{tabular}


Military Technical College Kobry El-Kobbah, Cairo, Egypt

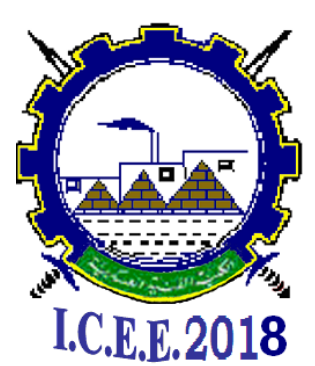

I.C.E.E. 2018

\section{$9^{\text {th }}$ International Conference on}

Chemical \& Environmental

Engineering

3-5 April 2018

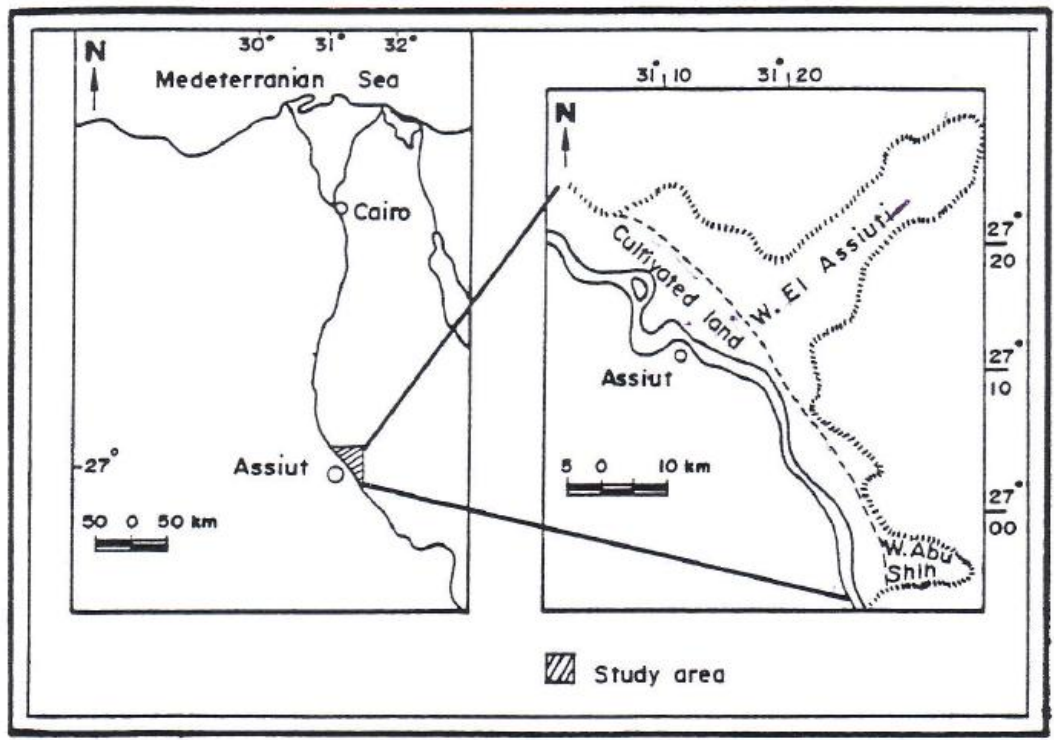

Fig (1): Map of study area

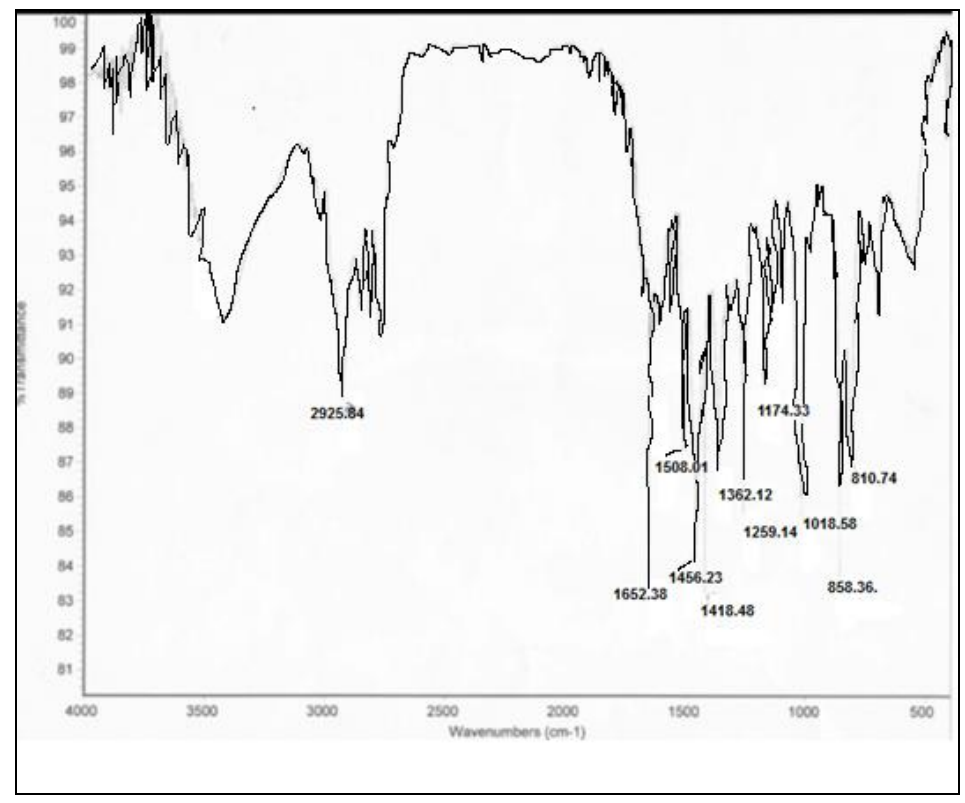

Fig (2): FT-IR Spectrum of Ion Exchange Amberlyst A21 
Military Technical College

Kobry El-Kobbah,

Cairo, Egypt

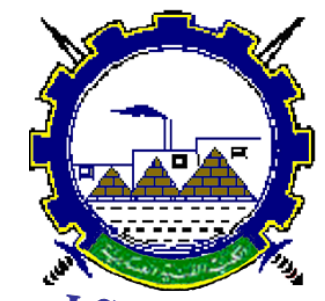

I.C.E.E.2018 $9^{\text {th }}$ International Conference on

Chemical \& Environmental

Engineering

3-5 April 2018

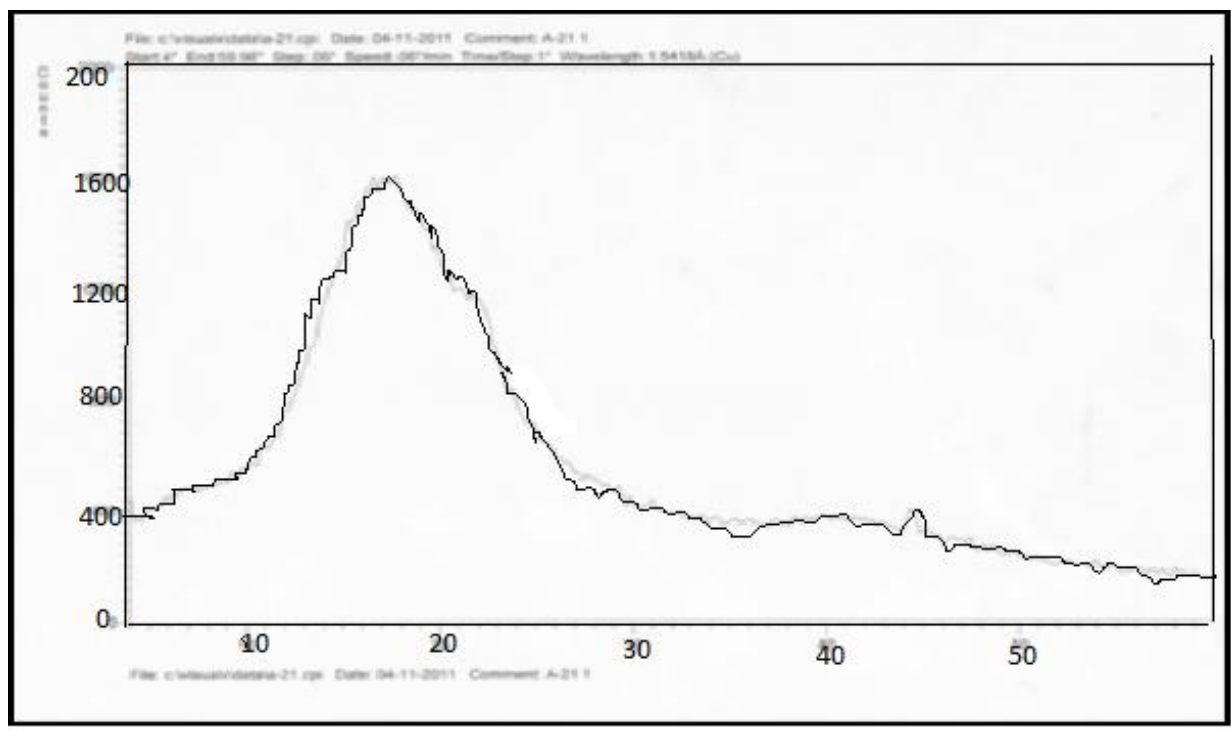

Fig (3): X-ray diffractogram of ion exchange Amberlyst A21

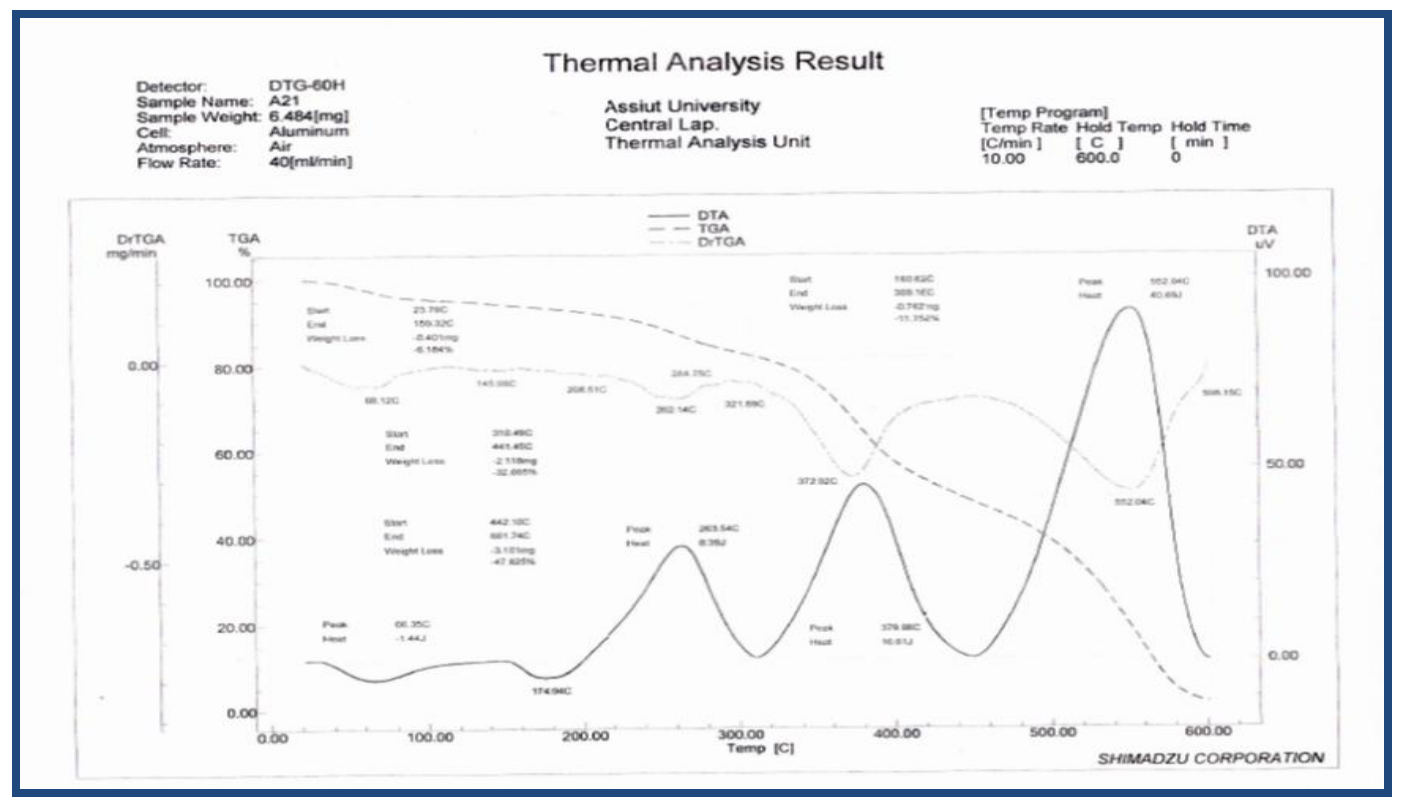

Fig (4) TGA and DTG diagram of Resin Amberlyst A21 in air at a heating rate of $10{ }^{\circ} \mathrm{C} / \mathrm{min}$ 
Military Technical College

Kobry El-Kobbah,

Cairo, Egypt

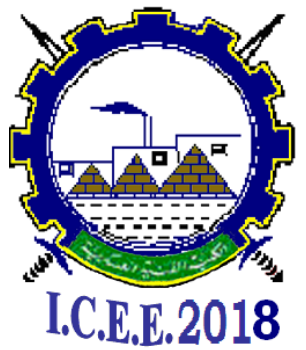

I.C.E.E. 2018 $9^{\text {th }}$ International Conference on

Chemical \& Environmental

Engineering

3-5 April 2018

A

B
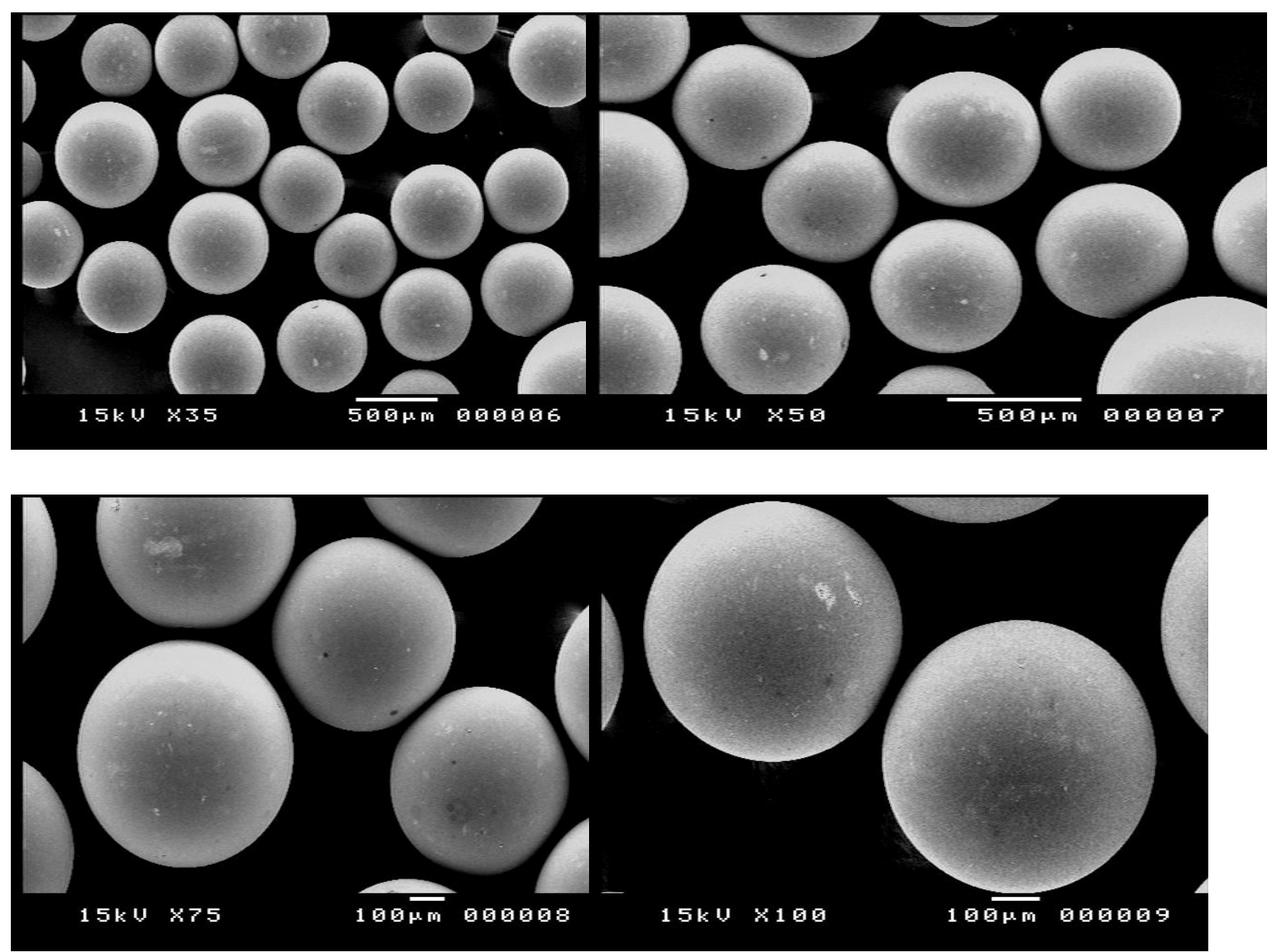

C

Fig (5): The SEM images of the resin surface of the resin Amberlyst A21

( $A, X=35, B, X=50, C, X=75$ and $D, X=100)$. 
Military Technical College

Kobry El-Kobbah, Cairo, Egypt

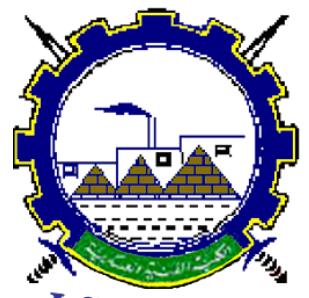

I.C.E.E.2018 $9^{\text {th }}$ International Conference

Chemical \& Environmental

Engineering

3-5 April 2018

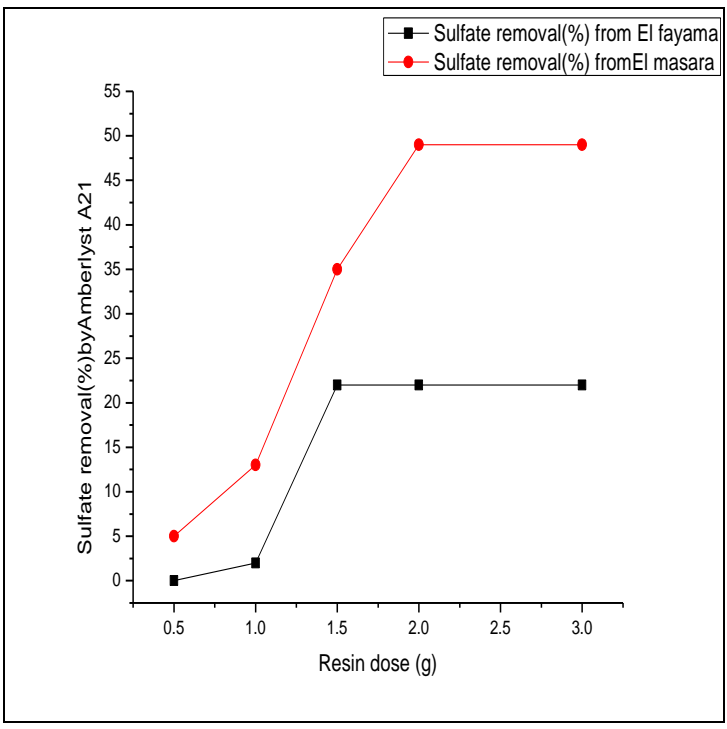

Fig (6): Results of effect of different resin dose on removal of Sulfate by (Amberlyst A21)

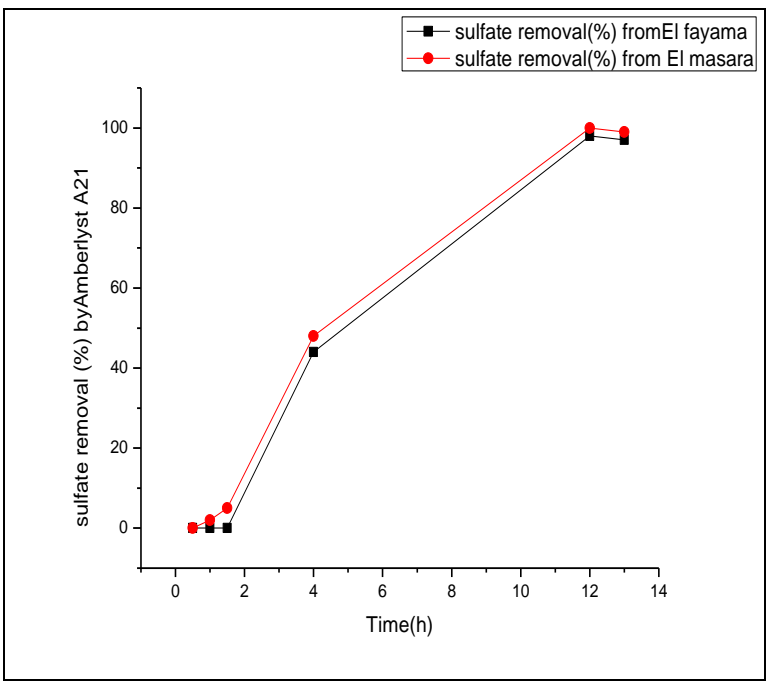

Fig (7): Results of effect of different time on removal of Sulfate by (Amberlyst A21) 
Military Technical College

Kobry El-Kobbah,

Cairo, Egypt

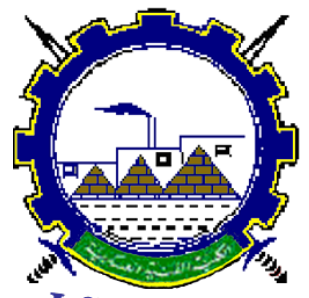

I.C.E.E.2018 $9^{\text {th }}$ International Conference on

Chemical \& Environmental

Engineering

3-5 April 2018

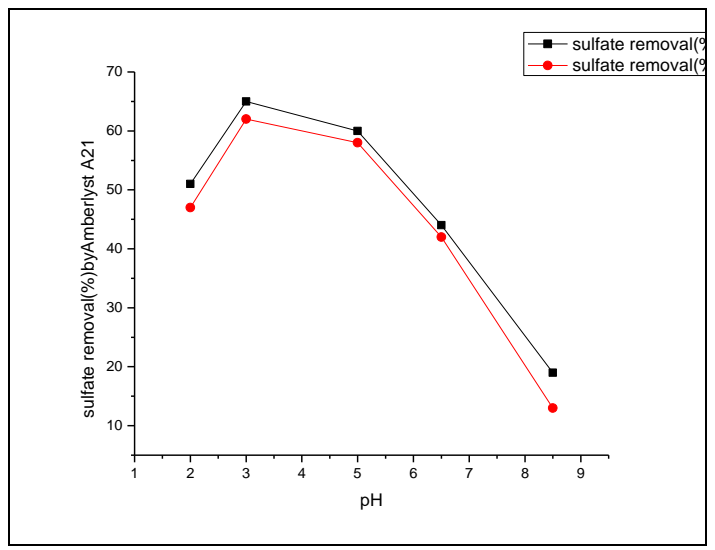

Fig (8): Results of effect of pH on removal of sulfate by (Amberlyst A21).
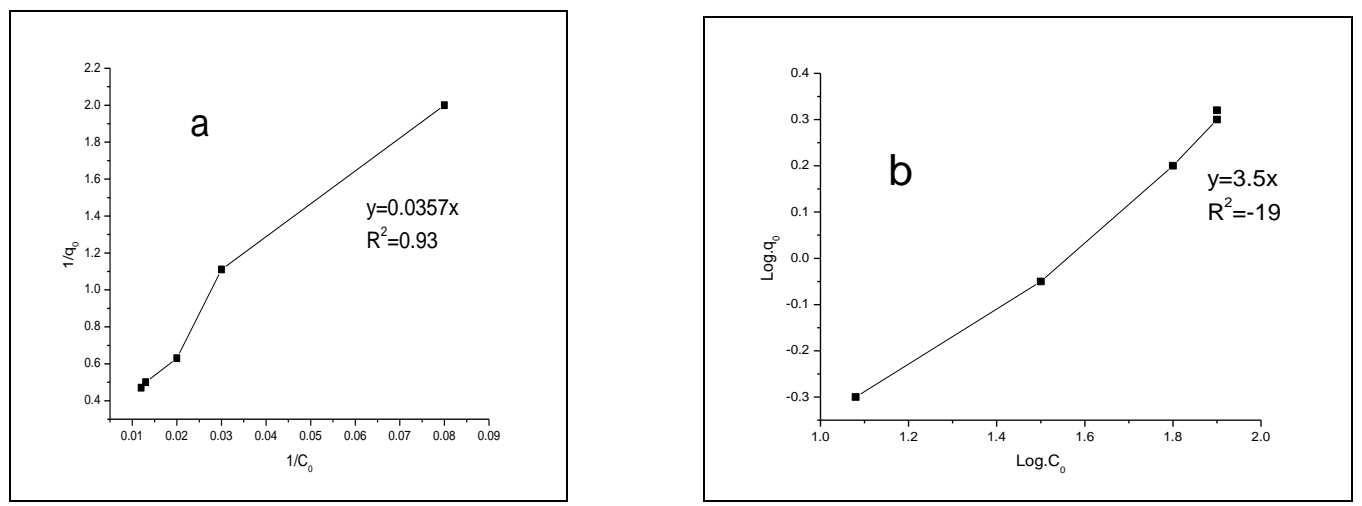

Fig (9) Equation for sulfate ion removal at various initial ion concentrations using ion exchange resin (Amberlyst A21)

(a) Langmuir adsorption and (b) Freundlich adsorption isotherm 